\title{
Avaliação de métodos de manutenção da esterilidade do órgão dental humano extraído para armazenamento em banco de dentes
}

\author{
Luciana Stadler Demenech*; Flávia Sens Fagundes Tomazinho**; Paulo Henrique Tomazinho*; \\ Marilisa Carneiro Leão Gabardo**; Flares Baratto-Filho** \\ * MSc. Programa de Pós-Graduação em Odontologia, \\ Universidade Positivo \\ ** PhD. Programa de Pós-Graduação em Odontologia, \\ Universidade Positivo
}

Recebido em 30/04/2017. Aprovado em 21/07/2017.

\begin{abstract}
RESUMO
A importância de um banco de dentes humanos em uma instituição de se justifica e se mostra vantajosa, uma vez que permite a máxima aproximação da realidade ao se trabalhar com o órgão extraído. Este estudo teve o propósito de avaliar métodos de manutenção da esterilidade do órgão dental humano extraído armazenado. Foram utilizados 72 dentes incisivos humanos extraídos, obtidos em clínicas de graduação e de pós-graduação da Universidade Positivo, Curitiba, PR, Brasil. Os elementos dentários foram cedidos pelos pacientes, por meio de termo de doação devidamente assinado. Após os procedimentos de limpeza e de desinfecção, 36 dentes foram esterilizados em autoclave e 36 foram somente limpos. Os dentes foram, então, armazenados em recipientes contendo o método (autoclavagem ou limpeza) ou a solução de escolha, por um período de 15 e 120 dias. Testes microbiológicos foram realizados a fim de determinar qual método ou solução de armazenamento promove a manutenção da esterilidade no tempo determinado. Melhores desempenhos foram observados quando as amostras foram armazenadas em Incidin Extra N®, formol e álcool, mesmo para os dentes não autoclavados. As substâncias em análise nos períodos propostos se mostraram capazes de impedir o crescimento microbiano. Este experimento poderá auxiliar o desenvolvimento de um protocolo de processamento e de administração do órgão dental humano extraído em um banco de dentes.
\end{abstract}

Descritores: Odontologia. Biossegurança. Esterilização. Dente. Técnicas microbiológicas.

\section{INTRODUÇÃO}

Um Banco de Dentes Humanos (BDH) é de suma importância para a instituição de ensino superior (IES), enquanto capaz de gerenciar o órgão dental humano extraído (ODHE), comumente utilizado em procedimentos laboratoriais pré-clínicos e em pesquisas em várias áreas da Odontologia ${ }^{1-3}$. Nesse cenário, é 
relevante a necessidade de se obter dentes de qualidade estrutural, evitando-se a ilegalidade e promovendo-se a manipulação segura do $\mathrm{ODHE}^{2}$. Para que este esteja em plenas condições de uso é importante que sua integridade seja preservada e se aproxime ao máximo das condições estruturais in vivo ${ }^{4,5}$.

Todo o processo de manipulação deve garantir que sejam mantidas as propriedades físicas, químicas e também mecânicas dos dentes, garantindo a manutenção da forma e composição teciduais, não influenciando de forma negativa estudos e pesquisas ${ }^{4,6}$. Para tanto, o meio de armazenamento, solução utilizada ou método de escolha, deve assegurar não somente a preservação da esterilidade durante determinado tempo, mas também a não alteração das propriedades estruturais do ODHE.

O manuseio indiscriminado dos dentes pode gerar riscos ao operador ou exposição ocupacional, além de infecção cruzada ${ }^{1,6}$. A presença de patógenos radiculares, perirradiculares e periodontais remanescentes, restos celulares e sujidades não deve ser ignorada $^{7,8}$.

Com a intenção de padronizar os procedimentos de manipulação e utilização dos ODHE em um BDH, a IES deve seguir um Protocolo Operacional Padrão (POP), o qual deve orientar desde a doação, realizada por escrito pelo paciente em um termo específico ${ }^{9}$, até o manuseio, armazenamento e distribuição desses dentes. A doação dos ODHE deve ser livre e consentida pelo paciente, respeitando os princípios éticos ${ }^{10}$. Deve-se também, padronizar o transporte, preparo prévio, desinfecção e/ou esterilização, melhor forma de armazenamento, empréstimo e também a devolução ou descarte dos dentes já utilizados ${ }^{1-3,7,11}$.

Para a elaboração de um POP, faz-se necessária a determinação clara de cada etapa, baseada em questões legais e científicas ${ }^{2}$. A etapa de armazenamento tem sido bastante estudada, porém, não há registros na literatura a respeito da manutenção da esterilidade do ODHE durante o período de armazenamento das amostras. As pesquisas existentes, em geral, avaliam a desinfecção e esterilização em autoclave dos dentes previamente ao armazenamento ${ }^{7,11-13}$. Quanto ao armazenamento, Campregher et al. ${ }^{4}$ observaram que não há consenso quanto ao melhor método ou meio de armazenamento. Os mais utilizados são a água destilada ${ }^{6,7}$, o soro fisiológico ${ }^{7,14}$, saliva $\operatorname{artificial}^{14}$, timol $^{6,15}$, formalina $^{12}$, hipoclorito de sódio ${ }^{13}$, álcool, solução de cloramina e o método de congelamento ou criopreservação ${ }^{16,17}$, além das possíveis alterações estruturais dos tecidos dentários, provocadas pelas soluções ou métodos utilizados $^{5,15,17}$.

Uma vez estabelecido um POP, a IES certificará que o ODHE está limpo, estéril e em boas condições para o estudo e práticas em laboratório. O estudante, dessa forma, não enfrentará dificuldades e evitará possíveis práticas ilegais $^{3,18,19}$.

Frente ao exposto, a presente pesquisa teve por objetivo avaliar métodos de manutenção da esterilidade do órgão dental humano extraído, durante o armazenamento.

\section{MATERIAL E MÉTODOS}

Esse estudo foi aprovado pelo Comitê de Ética em Pesquisa da Universidade Positivo, sob registro n. ${ }^{\circ}$ 58075516.4.0000.0093. Foram utilizados 72 dentes incisivos humanos extraídos, cedidos pelos pacientes das clínicas de graduação e de pós-graduação da Universidade Positivo, Curitiba, PR, Brasil, os quais assinaram de termo de doação do ODHE.

Os dentes foram submetidos à limpeza prévia realizada conforme as diretrizes do Centers for Disease Control and Prevention ${ }^{7} \mathrm{e}$ da American Dental Association ${ }^{11}$. Para tanto, 
foram utilizados escova e sabão detergente enzimático (ASPER, São Caetano do Sul, Brasil), seguidos de enxágue em água potável corrente durante um minuto. Depois foi feita a remoção de sujidades, tecido cariado e restaurações defeituosas ou em amálgama com broca esférica diamantada em alta e em baixa rotação (KG Sorensen $\AA$, Cotia, Brasil), sob refrigeração com água. Em adição, foi realizada uma raspagem radicular com curetas periodontais (Golgran ${ }$, São Caetano do Sul, Brasil) para a remoção de cálculo ou resíduos perirradiculares, a fim de promover uma superfície limpa e lisa, sem possíveis fatores de retenção ou nichos.

O fluxo do método adotado se encontra na figura 1. Para avaliar os métodos e soluções de armazenamento dos dentes, após o preparo prévio, os mesmos foram divididos aleatoreamente em dois grupos experimentais: Grupo 1 - dentes autoclavados a $121^{\circ} \mathrm{C}$ por 40 minutos $(n=36)$ e Grupo 2 - dentes somente limpos e não autoclavados $(n=36)$. Os grupos foram devidamente identificados e subdivididos em oito subgrupos, contendo cada, quatro dentes $(n=4)$. Foram armazenados oito dentes a mais, quatro autoclavados e quatro não autoclavados, pois para os testes do subgrupo de dentes congelados as amostras foram inseridas diretamente sobre a placa de Petri. Desta forma, para a nova análise em 120 dias, foram necessários mais dentes de cada grupo e subgrupo, respectivamente.

Os subgrupos foram divididos como segue: subgrupo A - Peresal ${ }^{\circledR}$ (Profilática, Araucária, Brasil); subgrupo B - Incidin Extra N® (Ecolab Deutschland $\mathrm{GmbH}$, Düsseldorf, Alemanha); subgrupo C - Cloramina T (Merck Millipore, Darmstadt, Alemanha); subgrupo D - água destilada; subgrupo E - soro fisiológico; subgrupo F - formol; subgrupo G - álcool 70\%; subgrupo $\mathrm{H}$ - dentes congelados. $\mathrm{O}$ subgrupo $\mathrm{H}$ foi armazenado em congelador a uma temperatura média de $-6{ }^{\circ} \mathrm{C}$.

As soluções de Peresal ${ }^{\circledR}$, Incidin Extra $N \circledast$ e Cloramina $\mathrm{T}$ foram preparadas seguindo as instruções dos fabricantes.

Cada dente foi armazenado em tubo de ensaio esterilizado submerso em $5 \mathrm{~mL}$ da solução de escolha, quantidade necessária para a imersão completa da amostra. No subgrupo de dentes congelados foi inserido um dente em cada tubo, sem a presença de solução.

As amostras foram armazenadas por um período inicial de 15 dias e avaliadas posteriormente por inspeção visual. Os tubos de ensaio contendo os dentes foram cuidadosamente agitados e os tubos que apresentaram turvamento visível da solução no qual o dente estava submerso, foram registrados como resultado positivo, ou seja, apresentaram crescimento de microrganismos. Já as amostras que não apresentaram turvamento foram registradas como resultado negativo, ou seja, sem crescimento bacteriano. O grupo de dentes congelados (subgrupo H) não foi avaliado nesta primeira análise, devido à ausência de meio líquido de armazenamento.

Na sequência foi retirada uma alíquota de $0,1 \mathrm{~mL}$ de cada tudo de ensaio e transferida para placas de Petri identificadas e divididas em quatro partes. As placas continham meio de cultura estéril (ágar sangue). Essa amostra foi semeada em um quarto da superfície da placa com o auxílio de uma alça bacteriológica. Esse teste foi realizado para confirmar o crescimento bacteriano nos tubos em que houve turvação da solução no qual os dentes estavam armazenados e também para verificar se não havia crescimento bacteriano nos tubos sem turvamento.

$\mathrm{O}$ subgrupo $\mathrm{H}$ foi inserido diretamente sobre a placa no espaço determinado. As amostras foram armazenadas em estufa a $37^{\circ} \mathrm{C}$ por 48 horas. Nova análise foi realizada por 
inspeção visual. As placas que apresentaram crescimento de colônias de microrganismos foram registradas como resultado positivo (figura 2A), enquanto as sem crescimento, como resultado negativo (figura $2 \mathrm{~B}$ ).

Os testes e análises foram repetidos no período de 120 dias de armazenamento, respeitando os mesmos procedimentos.

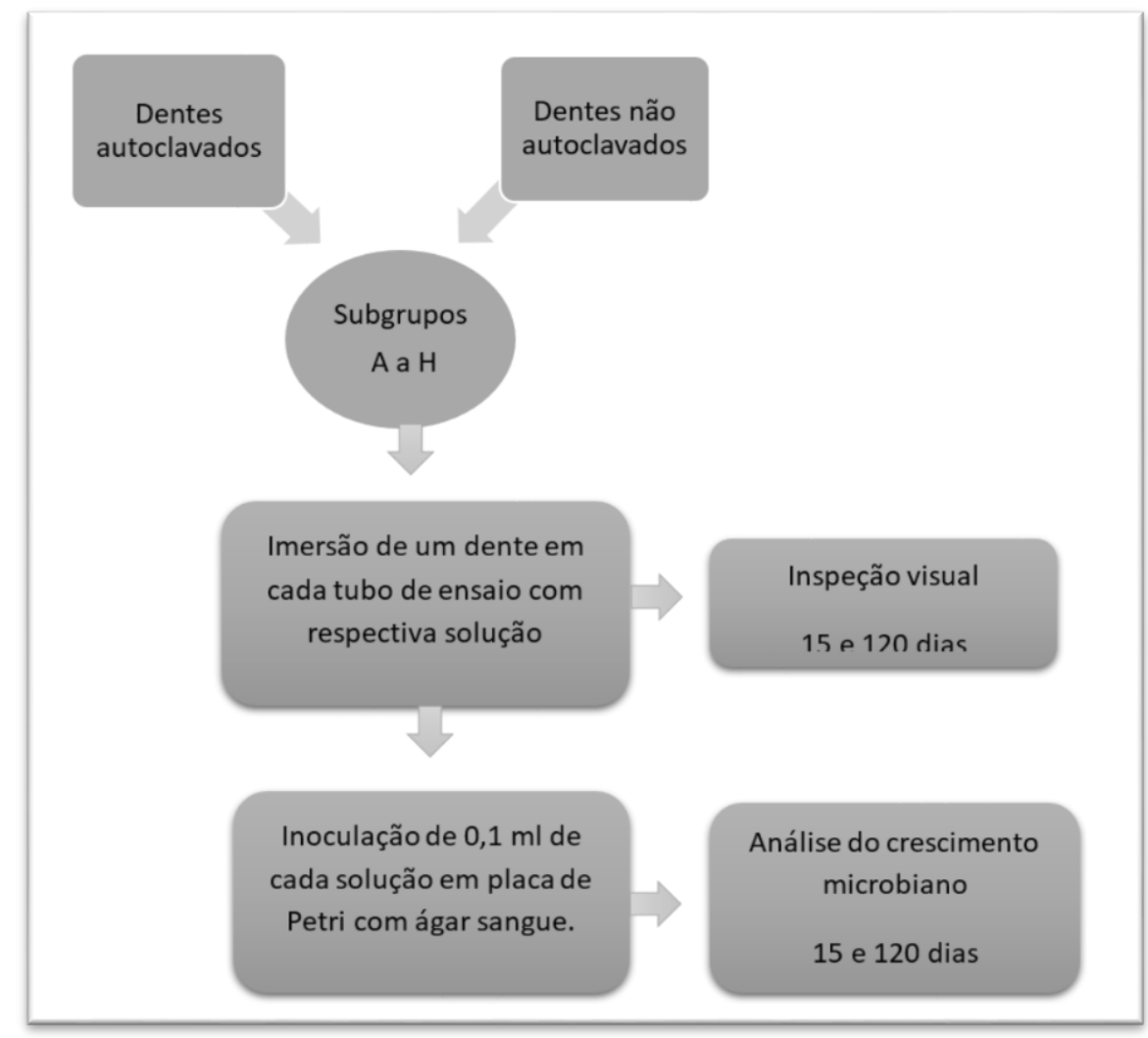

Figura 1. Fluxograma do método laboratorial.

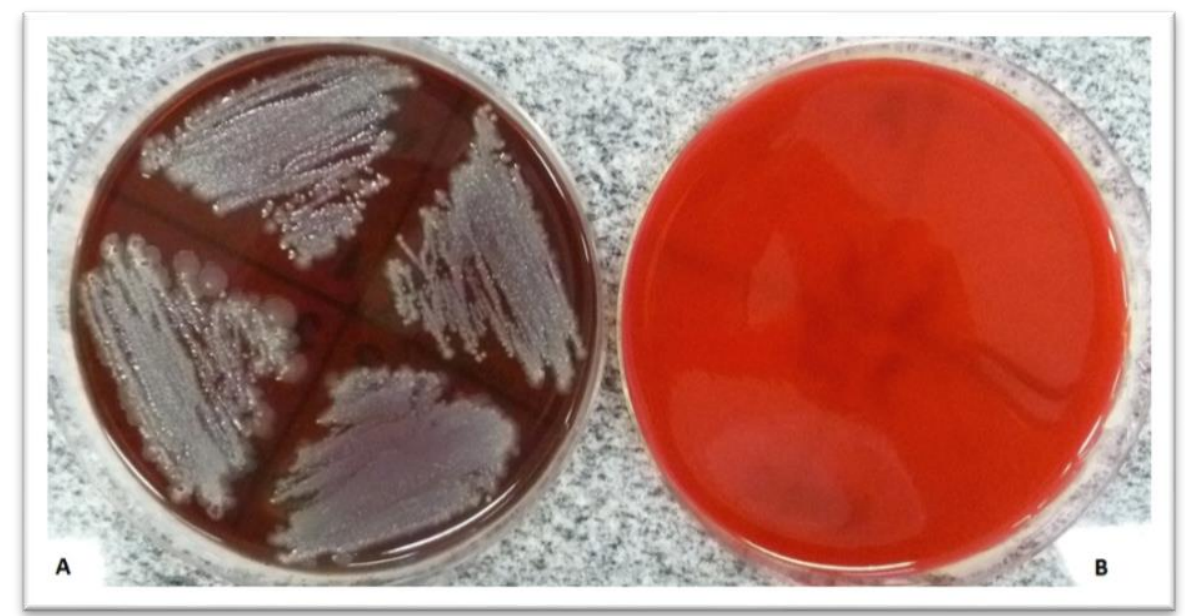

Figura 2. (A) Crescimento microbiano sobre ágar sangue, resultado positivo. (B) Ausência de crescimento microbiano sobre ágar sangue, resultado negativo. 


\section{RESULTADOS}

Os resultados da análise realizada em 15 dias de armazenamento estão expressos nas tabelas 1 e 2 .

A inspeção visual dos tubos de ensaio mostrou resultado positivo para o grupo 1 (dentes autoclavados), com os subgrupos: Cloramina $\mathrm{T}$ em três amostras e água destilada em uma amostra. Os demais subgrupos foram negativos para todas as amostras.

No grupo 2 (dentes não autoclavados) os resultados positivos foram para os subgrupos: Peresal ${ }^{\circledR}$ em três amostras, Cloramina $\mathrm{T}$, água destilada e soro fisiológico, em todas as amostras. Os demais subgrupos, Incidin Extra $\mathrm{N} 囚$, formol e álcool, foram negativos em todas as amostras. O subgrupo de dentes congelados não foi analisado neste momento, pois não foi inserido em meio líquido de armazenamento.

A segunda análise, em placas de Petri, apresentou resultado positivo para o grupo 1 (dentes autoclavados), nos subgrupos Cloramina T e água destilada, em uma amostra e em quatro amostras respectivamente. Já os outros subgrupos, Peresal ${ }^{\circledR}$, Incidin Extra $\mathrm{N} \circledast$, soro fisiológico, formol, álcool e dentes congelados, apresentaram resultado negativo em todas as amostras. O grupo 2 (dentes não autoclavados) apresentou resultado positivo para os seguintes grupos: Peresal ${ }^{\circledR}$ em três amostras e nos subgrupos Cloramina $\mathrm{T}$, água destilada, soro fisiológico e dentes congelados respectivamente, em todas as amostras. Obtiveram resultado negativo, os subgrupos Incidin Extra $\mathrm{N} \circledast$, formol e álcool, respectivamente, em todas as amostras.

Os resultados da análise em 120 dias de armazenamento estão expressos nas tabelas 3 e 4 . $\mathrm{Na}$ primeira análise mantiveram os mesmos resultados para o grupo 1, subgrupos Peresal ${ }^{\circledR}$, Incidin Extra $\mathrm{N} 囚$, formol e álcool, para 15 e 120 dias. Entretanto, para os subgrupos Cloramina $\mathrm{T}$ e água destilada, resultados positivos em todas as amostras, enquanto no subgrupo soro fisiológico uma amostra foi positiva em 120 dias. No grupo 2 (dentes não autoclavados), mantiveram os mesmos resultados para o armazenamento em 120 dias, os subgrupos Incidin Extra $\mathrm{N} \circledast$, Cloramina $\mathrm{T}$, água destilada, soro fisiológico, formol e álcool. Apresentou resultado diferente somente o subgrupo Peresal $\AA$, com todas as amostras positivas.

Tabela 1. Eficácia das soluções utilizadas para armazenamento dos dentes autoclavados na manutenção da ausência de crescimento microbiano, em análise de 15 dias.

\begin{tabular}{lcc}
\hline Subgrupos & \multicolumn{2}{c}{ Grupo Dentes autoclavados } \\
\hline Peresal ${ }^{\circledR}$ & $0 / 4$ & Cultura**/ Total \\
Incidin Extra N $®$ Total & $0 / 4$ & $0 / 4$ \\
Cloramina T & $3 / 4$ & $0 / 4$ \\
Água destilada & $1 / 4$ & $4 / 4$ \\
Soro fisiológico & $0 / 4$ & $1 / 4$ \\
Formol & $0 / 4$ & $0 / 4$ \\
Álcool 70\% & $0 / 4$ & $0 / 4$ \\
Congelados & $\mathrm{X}$ & $0 / 4$ \\
\hline
\end{tabular}

* Inspeção visual do crescimento microbiano em tubos de ensaio. ** Confirmação do crescimento microbiano em placa de cultura de ágar sangue. 
Tabela 2. Eficácia das soluções utilizadas para armazenamento dos dentes não autoclavados na manutenção da ausência de crescimento microbiano, em análise de 15 dias.

\begin{tabular}{lcc}
\hline & \multicolumn{2}{c}{ Grupo Dentes não autoclavados } \\
\hline Subgrupos & Visual*/ Total & Cultura**/ Total \\
\hline Peresal ${ }^{\circledR}$ & $3 / 4$ & $3 / 4$ \\
Incidin Extra N $®$ & $0 / 4$ & $0 / 4$ \\
Cloramina T & $4 / 4$ & $4 / 4$ \\
Água destilada & $4 / 4$ & $4 / 4$ \\
Soro fisiológico & $4 / 4$ & $4 / 4$ \\
Formol & $0 / 4$ & $0 / 4$ \\
Álcool 70\% & $0 / 4$ & $0 / 4$ \\
Congelados & $\mathrm{X}$ & $4 / 4$ \\
\hline
\end{tabular}

*Inspeção visual do crescimento microbiano em tubos de ensaio. ** Confirmação do crescimento microbiano em placa de cultura de ágar sangue.

Tabela 3. Eficácia das soluções utilizadas para armazenamento dos dentes autoclavados na manutenção da ausência de crescimento microbiano, em análises de 120 dias.

\begin{tabular}{lcc}
\hline & \multicolumn{2}{c}{ Grupo Dentes autoclavados } \\
\hline \multicolumn{1}{c}{ Subgrupos } & Visual*/ Total & Cultura**/ Total \\
\hline Peresa $^{\circledR}$ & $0 / 4$ & $0 / 4$ \\
Incidin Extra N $^{\circledR}$ & $0 / 4$ & $0 / 4$ \\
Cloramina T & $4 / 4$ & $4 / 4$ \\
Água destilada & $4 / 4$ & $4 / 4$ \\
Soro fisiológico & $1 / 4$ & $4 / 4$ \\
Formol & $0 / 4$ & $0 / 4$ \\
Álcool 70\% & $0 / 4$ & $0 / 4$ \\
Congelados & $\mathrm{X}$ & $0 / 4$ \\
\hline ção visual do crescimento microbiano em tubos de ensaio. ${ }^{* *}$ Confirmação do crescimento \\
\end{tabular}

Tabela 4. Eficácia das soluções utilizadas para armazenamento dos dentes não autoclavados na manutenção da ausência de crescimento microbiano, análise em 120 dias.

\begin{tabular}{lcc}
\hline & \multicolumn{2}{c}{ Grupo Dentes não autoclavados } \\
\hline Subgrupos & Visual*/ Total & Cultura**/ Total \\
\hline Peresal ${ }^{*}$ & $4 / 4$ & $4 / 4$ \\
Incidin Extra N® & $0 / 4$ & $0 / 4$ \\
Cloramina T & $4 / 4$ & $4 / 4$ \\
Água destilada & $4 / 4$ & $4 / 4$ \\
Soro fisiológico & $4 / 4$ & $4 / 4$ \\
Formol & $0 / 4$ & $0 / 4$ \\
Álcool 70\% & $0 / 4$ & $0 / 4$ \\
Congelados & $\mathrm{X}$ & $4 / 4$ \\
\hline
\end{tabular}

* Inspeção visual do crescimento microbiano em tubos de ensaio. ** Confirmação do crescimento microbiano em placa de cultura de ágar sangue 
$\mathrm{Na}$ segunda análise, no grupo de dentes autoclavados, os resultados se mantiveram, exceto para o subgrupo água destilada e soro fisiológico, que apresentaram crescimento em todas as amostras. Para o grupo de dentes não autoclavados, o subgrupo Peresal ${ }^{\circledR}$ foi o único que obteve resultado diferente ao analisado no primeiro período (15 dias), apresentando todas as amostras com crescimento em 120 dias.

\section{DISCUSSÃO}

Diversos estudos têm sido realizados com o intuito de determinar a eficácia das soluções, métodos de limpeza, desinfecção e/ou esterilização dos dentes extraídos, bem como para encontrar o método ideal de armazenamento dos mesmos em um $\mathrm{BDH}^{4-6,12,14,20}$. Contudo, a capacidade de se manter a esterilidade do ODHE durante o armazenamento tem sido ignorada.

A fim de eliminar, ou ao menos reduzir o risco de contaminação durante o manuseio dos dentes nos procedimentos laboratoriais e de pesquisa, é importante que se estabeleça uma rotina ou um protocolo de limpeza, desinfecção e/ou esterilização ${ }^{1}$. Para tanto, é necessário que se estabeleça a eficácia dos métodos e das soluções a serem utilizados para se obter limpeza e esterilização ideais ${ }^{8}$, de modo a não comprometer a estrutura dos tecidos dentários ${ }^{5,21}$.

Os métodos ou as soluções utilizadas para a desinfecção e/ou esterilização do ODHE devem garantir uma ação biocida, ou seja, com capacidade de eliminar microrganismos, de alto nível ${ }^{12,20}$.

No presente estudo foi realizada a limpeza/desinfecção e esterilização, conforme revisão de literatura pesquisada ${ }^{7,11}$. Optou-se por esterilizar os dentes em autoclave, previamente ao armazenamento, em virtude da Resolução da Diretoria Colegiada (RDC) da Agência Nacional de Vigilância Sanitária, n. ${ }^{\circ}$ 35, de 16 de agosto de
2010, que impede a utilização de soluções desinfetantes para a esterilização de artigos críticos e semicríticos ${ }^{22}$.

Além da limpeza e desinfecção manuais, outra possibilidade é a utilização da limpeza automatizada, por meio de lavadora ultrassônica. Segundo DeWald ${ }^{23}$ o uso do ultrassom favorece a remoção de resíduos em camadas mais profundas, promovendo uma limpeza mais eficaz em regiões de difícil acesso. Devido à necessidade de tornar o protocolo de processamento do $\mathrm{BDH}$ passível de implementação, optou-se pela praticidade da técnica e redução de etapas. Sendo assim, foi realizada somente a limpeza e a desinfecção manual das amostras.

O álcool $70 \%$ apresentou bons resultados, com ausência de crescimento microbiano nas amostras nos tempos analisados, mesmo em dentes não autoclavados. Porém, por ser volátil, observa-se a evaporação da solução com o passar do tempo de armazenamento, especialmente em 120 dias. A reposição da solução ao longo do período de armazenamento torna-se necessária, requerendo assim, a nova intervenção de um operador e novo risco de contaminação ${ }^{24}$. Ademais, o álcool pode desidratar os tecidos dentários e os meios de armazenagem devem ser utilizados para prevenir a desidratação dos espécimes, além de controlar alterações no pH e evitar o crescimento microbiano ${ }^{25}$.

Com o formol foram revelados resultados satisfatórios, também em amostras não autoclavadas. Entretanto, essa substância traz riscos a quem a manipula ${ }^{26,27}$. Estudos longitudinais de exposição ao formaldeído têm mostrado evidências de um aumento na incidência de câncer de nasofaringe ${ }^{26}$ e uma associação causal com leucemia mielóide e adenocarcinoma nasossinusal ${ }^{27}$. Para haver segurança, as soluções de formol só devem ser manuseadas dentro de um fluxo laminar, que 
pode não estar disponível, expondo o operador a risco de contaminação.

O congelamento é um método bastante estudado para armazenamento do ODHE $^{16,17}$. Apesar de ser considerado fácil, prático e de baixo custo, os resultados do presente estudo foram positivos somente em dentes autoclavados. Nas amostras não autoclavadas o crescimento de colônias foi observado em todos os casos, o que torna indispensável a esterilização prévia. A vantagem deste método se refere ao menor risco de exposição da amostra, uma vez que não é necessária a troca ou a reposição como no caso das soluções. Além disso, pode ocupar menos espaço durante o armazenamento, no que diz respeito à organização e ao processamento dos dentes que serão futuramente emprestados ${ }^{17}$.

Com relação à esterilização em autoclave, estudos têm sido realizados para determinar a influência sobre os tecidos dentários. Segundo Pashley et $a l^{21}$, a esterilização de dentes em autoclave, quando analisada a permeabilidade dentinária, não promove alterações significantes. Em contrapartida, Parsell et al. ${ }^{28}$, analisaram os efeitos da autoclavagem em dentes extraídos por meio de teste de microdureza e percepção de corte. Os autores observaram alterações nas amostras submetidas à autoclave nos testes de microdureza do esmalte. Achados de SalemMilani et al. ${ }^{29}$ corroboram estes resultados, entretanto com referência à análise de microdureza dentinária. Para os autores, que seguiram o protocolo do CDC, a imersão em formalina a $10 \%$ foi recomendada.

Quanto à água destilada, no presente estudo, a mesma foi utilizada como grupo controle. Optou-se também pela esterilização apenas da metade das amostras, com a intenção de se obter um controle positivo e outro negativo. Isto se justifica pelo fato de a esterilização em autoclave ter o poder, ou não, de alterar significativamente as propriedades dos tecidos dentários, segundo consta na literatura, considerada controversa ${ }^{19,28}$.

Além de manter os dentes estéreis, pelo tempo determinado de armazenamento, as soluções ou métodos de escolha, devem garantir a manutenção das propriedades físico-químicas do ODHE. A permeabilidade dos tecidos, a dureza do esmalte e a adesão dentinária devem ser consideradas. De acordo com Silva et al. ${ }^{6}$, as pesquisas ou situações laboratoriais, devem simular as condições do meio bucal, a exemplo dos testes de propriedades mecânicas dos materiais restauradores adesivos. Se o método de esterilização, ou ainda de armazenamento do ODHE, alterar tais propriedades, a pesquisa torna-se inviável.

Em 1985, Williams e Svare $^{30}$ realizaram pesquisa com dentes armazenados em água destilada e timol a $4^{\circ} \mathrm{C}$ por 24 horas, em três meses e cinco anos. Após esses períodos os dentes foram armazenados por uma semana em água destilada e submetidos ao teste de cisalhamento. Os resultados não demonstraram diferenças estatisticamente significativas entre os valores de resistência. Da mesma forma, Oh et $a l .{ }^{17}$ ao realizarem testes de dureza em dentes congelados não encontraram diferenças significativas entre o grupo controle e o grupo de dentes congelados.

Os resultados obtidos por Goodis et al. ${ }^{15,31}$ revelaram diferenças significativas na permeabilidade dentinária e resistência adesiva dos dentes armazenados. Após armazenagem em álcool $70 \%$, formalina $10 \%$, água destilada com timol e soro fisiológico com timol, nos períodos de um, dois, quatro, oito, 15 e 22 dias, observouse que a permeabilidade foi menor para os dentes armazenados em etanol ou formalina. Com relação ao tempo, todas as amostras tiveram aumento da permeabilidade ${ }^{31}$. Em um segundo estudo, foi avaliada a influência de cinco 
soluções: álcool $70 \%$, formalina $10 \%$, água destilada com timol $0,02 \%$, água destilada e soro fisiológico com timol a $0,02 \%$. Foram realizados testes de resistência adesiva com oito e 15 dias e seis meses. Os valores de resistência adesiva indicaram alteração significativa nas amostras armazenadas em soro fisiológico ${ }^{15}$.

Testes laboratoriais para avaliar as propriedades físico-químicas dos ODHE armazenados para esse estudo devem ser realizados após o período de tempo determinado, para os diferentes métodos de armazenamento. Assim, pode-se determinar o método que apresenta o melhor desempenho, tanto na manutenção da esterilidade quanto na integridade dos tecidos dentários. Não se deve esquecer que a praticidade, o baixo custo e a facilidade de obtenção e utilização dos produtos, devem ser considerados.

Neste estudo optou-se pela não utilização do timol, solução utilizada para armazenamento do ODHE já relatada na literatura ${ }^{6,15}$. Normas vigentes para a compra do timol em estabelecimentos comerciais específicos (farmácias de manipulação), impedem a aquisição em grande escala sem a autorização e solicitação prévia por escrito de um responsável técnico de laboratório de pesquisa ${ }^{32}$. Tal fato dificulta a utilização do produto e torna inviável um protocolo de processamento de $\mathrm{BDH}$ prático e funcional, somado ao alto custo do produto quando empregado em larga escala.

Vale ressaltar que o armazenamento do ODHE em um BDH pode ser uma etapa simples e segura no que diz respeito à facilidade de manuseio, manutenção da esterilidade das amostras e integridade dos tecidos dentários, garantindo a futura utilização dos dentes em estudos e pesquisas. A estruturação de um BDH em uma IES de modo organizado e que cumpra suas principais funções é fundamental. Além da facilidade de o aluno em adquirir o modelo ideal de estudo para práticas laboratoriais, há um aumento notório da qualidade do aprendizado, visto que algumas atividades práticas com o ODHE simulam a realidade $e^{3,18,19}$.

Apesar da grande importância e benefícios, muitas IES ainda não possuem um $\mathrm{BDH}$, ou ainda, se possuem, não consolidaram um POP apropriado. Somado a isso, mais informações à comunidade a respeito da doação e ações efetivas na própria IES devem ser tomadas por parte de alunos, professores e coordenadores dos cursos em prol do avanço da Odontologia.

\section{CONCLUSÃO}

O Incidin Extra $\mathrm{N} \circledast$, assim como o formol e o álcool, após armazenamento em 15 e 120 dias, apresentou os melhores resultados, impedindo o crescimento microbiano, mesmo em dentes não autoclavados.

\section{ABSTRACT \\ Evaluation of methods for maintaining sterility of the extracted human dental organ during storage in a tooth bank}

The importance of a human teeth bank in an institution is justified and it is advantageous, since it allows the maximum approximation of reality when working with the extracted organ. This study aimed to evaluate methods for maintaining the sterility of extracted human teeth during storage. A total of 72 human incisors extracted in the undergraduate and graduate clinics of Universidade Positivo (Curitiba, PR, Brazil) were used in this study. The teeth were provided by patients, who signed a donation form. After all teeth were subjected to cleaning and disinfection procedures, 36 teeth were autoclaved as well. Teeth were then stored in various solutions for periods of 15 and 120 days. Microbiological tests were conducted to determine which method or storage promoted maintenance of sterility. Better results were obtained for teeth - including autoclaved teeth stored in Incidin Extra $\mathrm{N}^{\circledR}$, formaldehyde, and alcohol. The solutions analyzed over the proposed time periods have been shown to 
prevent microbial growth. Results of this study will aid in developing a protocol of processing for extracted human dental teeth to be stored in a tooth bank.

Descriptors: Dentistry. Biosecurity. Sterilization. Tooth. Microbiological Techniques.

\section{REFERÊNCIAS}

1. Nassif ACS, Tieri F, Ana PA, Botta SB, Imparato JCP. Structuralization of a Human Teeth Bank. Pesqui Odontol Bras. 2003; 17(Supl 1):70-4.

2. Vanzelli M, Imparato JCP. Banco de dentes: uma ideia promissora. Rev Stomatos. 2003; 9(16):59-60.

3. Moreira L, Genari B, Stello R, Collares FM, Samuel SMW. Banco de Dentes Humanos para o ensino e pesquisa em Odontologia. Rev Fac Odontol. 2009; 50(1):34-7.

4. Campregher UB, Arruda FZ, Samuel SMW. Meios utilizados para armazenagem de dentes em pesquisas odontológicas de impacto: uma revisão sistemática. RPG Rev Pos Grad. 2007; 14(2):107-12.

5. Lee JJ, Nettey-Marbell A, Cook AJr, Pimenta LA, Leonard R, Ritter AV. Using extracted teeth for research: the effect of storage medium and sterilization on dentin bond strengths. J Am Dent Assoc. 2007; 138(12):1549-603.

6. Silva MF, Mandarino, F, Sassi, JF, Menezes M, Centola ALB, Nonaka T. Influência do tipo de armazenamento e do método de desinfecção de dentes extraídos sobre a adesão à estrutura dental. Rev Odontol Univ Cid São Paulo. 2006; 18(2):175-80.

7. Centers for Disease Control and Prevention. Guidelines for infection control in dental health-care settings. MMWR. 2003; 52(RR17):1-61.

8. Mathieu L, Fleurette J, Transy MJ. The tooth transplantations: formation of a tooth bank and problems of sterilization. Ann Odontostomatol (Lyon). 1970; 27(1):13-25.

9. Imparato JCP. A utilização de dentes humanos, em pesquisas, treinamento acadêmico e/ou profissional e procedimentos clínicos. J Bras Clin Estet Odonto. 2000; 4(22):9.

10. Marsicano JA, Ramos Júnior ES, Assumpção TS, Sales-Peres SHC, Sales-Peres A. Pesquisa em seres humanos: aspectos médicos, jurídicos, psicológicos e religiosos. RGO. 2008; 56(3):327-32.

11. American Dental Association. Handling extracted teeth. Chicago; 2003 [acesso em 12 jan 2016]. Disponível em: http://www.ada.org/sections/professionalRes ources/pdfs/cdc_handling_extracted.pdf.

12. Kumar M, Sequeira PS, Peter S, Bhat GK. Sterilization of extracted human teeth for educational use. Indian $\mathrm{J}$ Med Microbiol. 2005; 23(4):256-8.

13. Costa S, Mameluque S, Brandão E, Melo A, Pires C, Rezende E, et al. Dentes humanos no ensino odontológico: procedência, utilização, descontaminação e armazenamento pelos acadêmicos da UNIMONTES. Rev ABENO. 2007; 7(1):6-12.

14. Kantoor P, Srivastava N, Rana V, Adlakha VK. Alterations in the mechanical properties of the extracted human teeth to be used as biological restorations on storing them in different storage media: an in vitro study. Dent Traumatol. 2015; 31(4):308-13.

15. Goodis HE, Marshall Jr GW, White JM, Gee L, Homberger B, Marshall SJ. Storage effects on dentin permeability and shear bond strengths. Dent Mater. 1993; 9(2):79-84.

16. Francescut P, Zimmerli B, Lussi A. Influence of different storage methods on laser fluorescence values: a two-year study. Caries Res. 2006; 40(3):181-5.

17. Oh YH, Che ZM, Hong JC, Lee EJ, Lee SJ, 
Kim J. Cryopreservation of human teeth future organization of a tooth bank - a preliminary study. Cryobiology. 2005; 51(3):322-9.

18. Freitas ABDA, Pinto SL, Tavares EP, Barros LM, Castro CDL. Uso de dentes humanos extraídos e os bancos de dentes nas instituições brasileiras de ensino de odontologia Pesqui Bras Odontopediatria Clín Integr. 2012;12(1):59-64.

19. Moreno Takehara GN, Morales Vadillo R, Guevara Canales JO, Reskalla HNJF, Chaves MGAM, Resende Do Carmo AM. Uso de dientes humanos en la enseñanza odontológica: aspectos éticos, legales y de bioseguridad. Acta Odontol Venez. 2012; 50(2).

20. Tijare M, Smitha D, Kasetty S, Kallianpur S, Gupta S, Amith H. Vinegar as a disinfectant of extracted human teeth for dental educational use. J Oral Maxillofac Pathol. 2014;18(1):14-8.

21. Pashley EL, Tao L, Pashley DH. Sterilization of human teeth: its effect on permeability and bond strength. Am J Dent. 1993;6(4):189-91.

22. Brasil. Ministério da Saúde. Resolução da Diretoria Colegiada - RDC n. 35, de 16 de agosto de 2010. Brasília; 2010. [Acesso em 15 jul 2016]. Disponível em: http://portal. anvisa.gov.br/wps/wcm/connect/8e68348047 fe3519bc9cbe9f306e0947/RDC+35+2010.pd $\mathrm{f}$ ?MOD=AJPERES.

23. DeWald JP. The use of extracted teeth for in vitro bonding studies: A review of infection control considerations. Dent Mater. 1997; 13(2):74-81.

24. Cunha AF, Miranda AMF, Rodrigues CT, Daú GL, Lech J, Possari JF, et al. Recomendações práticas para processos de esterilização em estabelecimentos de saúde: guia elaborado por enfermeiros brasileiros. 1. ed. São Paulo: Komedi; 2000. p.11-61.
25. Ziskind D, Gleitman J, Rotstein I, Friedman M. Evaluation of cetylpydinium chloride for infection control in storage solution. J Oral Rehab 2003; 30(5):477-81.

26. Hauptmann M, Lubin JH, Stewart PA, Hayes RB, Blair A. Mortality from solid cancers among workers in formaldehyde industries. Am J Epidemiol. 2004; 159(12):1117-30.

27. Hauptmann M, Lubin JH, Stewart PA, Hayes RB, Blair A. Mortality from lymphohematopoietic malignancies among workers in formaldehyde industries. J Natl Cancer Inst. 2003; 95(21):1615-23.

28. Parsell DE, Stewart BM, Barker JR, Nick TG, Karns L, Johnson RB. The effect of steam sterilization on the physical properties and perceived cutting characteristics of extracted teeth. J Dent Educ. 1998; 62(3):260-3.

29. Salem-Milani A, Zand V, Asghari-Jafarabadi M, Zakeri-Milani P, Banifatemeh A. The effect of protocol for disinfection of extracted teeth recommended by center for disease control (CDC) on microhardness of enamel and dentin. J Clin Exp Dent. 2015; 7(5): e552-6.

30. Williams VD, Svare CW. The effect of fiveyear storage prior to bonding on enamel/composite Bond strength. J Dent Res.1985; 64(2):151-4.

31. Goodis HE, Marshall Jr GW, White JM. The effects of storage after extraction of the teeth on human dentine permeability in vitro. Arch Oral Biol. 1991; 36(8):561-6.

32. Brasil. Agência Nacional de Vigilância Sanitária. Segurança do paciente em serviços de saúde: limpeza e desinfecção de superfícies. Brasília; 2010. 116 p.

Correspondência para:

Marilisa Carneiro Leão Gabardo

e-mail: marilisagabardo@gmail.com

Rua Prof. Pedro Viriato Parigot de Souza, 5300 81280-330 Curitiba, PR 